Natural Hazards and Earth System Sciences (2001) 1: 37-42

(C) European Geophysical Society 2001

Natural Hazards and Earth System Sciences

\title{
ULF/ELF emissions observed in Japan, possibly associated with the Chi-Chi earthquake in Taiwan
}

\author{
K. Ohta ${ }^{1}$, K. Umeda ${ }^{1}$, N. Watanabe ${ }^{1}$, and M. Hayakawa ${ }^{2}$ \\ ${ }^{1}$ Dept. of Electronic Engineering, Chubu University, 1200 Matsumoto, Kasugai, Aichi 487-8501, Japan \\ ${ }^{2}$ Dept. of Electronic Engineering, University of Electro-Communications, 1-5-1 Chofugaoka, Chofu, Tokyo 182-8585, Japan
}

Received: 7 May 2001 - Accepted: 23 July 2001

\begin{abstract}
ULF/ELF emission observation has been performed at Nakatsugawa observatory (geographic coordinates; $35.4^{\circ} \mathrm{N}, 137.5^{\circ} \mathrm{E}$, Gifu prefecture) since January 1999. The equipment consists of three-orthogonal magnetic sensors (induction coils), amplifiers, A/D converters and the data logger with a computer. The frequency range of observation is from $0.001 \mathrm{~Hz}$ to $50 \mathrm{~Hz}$. The serious changes in ELF magnetic field intensity were detected on 20 September 1999, in such a way that the ELF noise level is found to increase by more than $5 \mathrm{~dB}$ from the normal level for about 1.5 h during 21:30-23:00 Japanese Standard Time on 20 September and also the upper limit extends up to $50 \mathrm{~Hz}$. A careful comparison with the nearby lightning as detected by VLF, enables us to confirm that this abnormal ELF noise level increase is not due to the nearby lightning. The phase difference of these ELF emissions $\left(B_{X}, B_{Y}\right)$ was measured, and indicates that these ELF emissions are linearly polarized, suggesting that they have propagated in the subionospheric waveguide over long distances. This polarization result enables us to perform goniometric direction finding and the result shows that the main direction of these ULF/ELF emissions is toward Taiwan. Hence, it is likely that such ULF/ELF emissions are associated with the Chi-Chi earthquake in Taiwan at 02:27 Japanese Standard Time on 21 September $1999(M=7.6$; depth $11 \mathrm{~km})$.
\end{abstract}

\section{Introduction}

Electromagnetic phenomena have recently been considered as a promising candidate for short-term earthquake prediction (e.g. Hayakawa and Fujinawa, 1994; Hayakawa, 1999). Since the pioneering work by Gokhberg et al. (1982) in the LF band, there has been much evidence of precursory signatures in a wide frequency range from ULF to VHF. The lower frequency range (ULF/ELF) is especially promising, because

Correspondence to: M. Hayakawa

(hayakawa@whistler.ee.uec.ac.jp) there have been convincing reports of ULF signatures for recent large earthquakes (Spitak earthquake (Kopytenko et al., 1990; Molchanov et al., 1992), Loma Prieta earthquake (Fraser-Smith et al., 1990), Guam earthquake (Hayakawa et al., 1996; Kawate et al., 1998; Hayakawa et al., 1999), Biak earthquake (Hayakawa et al., 2000)), whose magnitude was always greater than 7.0 (or very close to 7.0). However, we need to accumulate more data on the presence of the ULF/ELF signature for earthquakes.

The earthquake which we will analyze, took place at ChiChi in Taiwan at 02:17 JST (Japanese Standard Time) (the local time in Taiwan is 01:47 LT) on 21 September 1999, with magnitude $M=7.6$ and with depth $\sim 11 \mathrm{~km}$. In this paper, we will report on ULF/ELF signature for this large earthquake, which was observed in Japan, about $2000 \mathrm{~km}$ from Taiwan.

\section{Observation of ULF/ELF emissions at Nakatsugawa, Japan and analysis method}

ULF/ELF measurements have been performed since January, 1999 at a field site, Nakatsugawa observatory located at Nakatsugawa (Nakatsugawa city in Gifu Prefecture; geographic coordinates, $35.4^{\circ} \mathrm{N}, 137.5^{\circ} \mathrm{E}$; geomagnetic latitude, $25.2^{\circ} \mathrm{N}$ ) at the foot of Mt. Ena, as shown in Fig. 1. As shown in the figure, our field site is far from civilization so that the electromagnetic environment is extremely good for ULF/ELF observations.

The observation system of ULF/ELF emissions at Nakatsugawa is shown in Fig. 2. Three magnetic components $\left(B_{X}, B_{Y}, B_{Z}\right)$ of ULF/ELF emissions are detected with three mutually orthogonal induction coils (each coil consists of perm alloy of $1.2 \mathrm{~m}$ long with 100000 turns of the copper wire) and they are fed to the $66 \mathrm{~dB}$ amplifiers with lowpass-filters (LPF) of $10 \mathrm{~Hz}$ and $30 \mathrm{~Hz}$. The data from each channel, digitized with a sampling frequency of $100 \mathrm{~Hz}$, are recorded on the data recording device (DL-708 YOKOGAWA ELECTRIC) and then saved on a Hard Disk every 


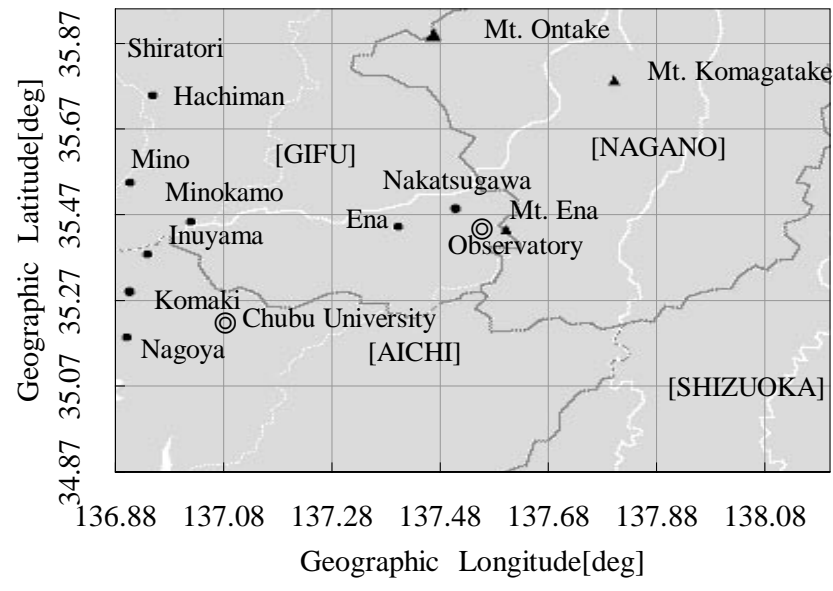

Fig. 1. The location of Nakatsugawa ULF/ELF observatory. Nakatsugawa is located in a low-noise site, far from the industrialized city of Nagoya.

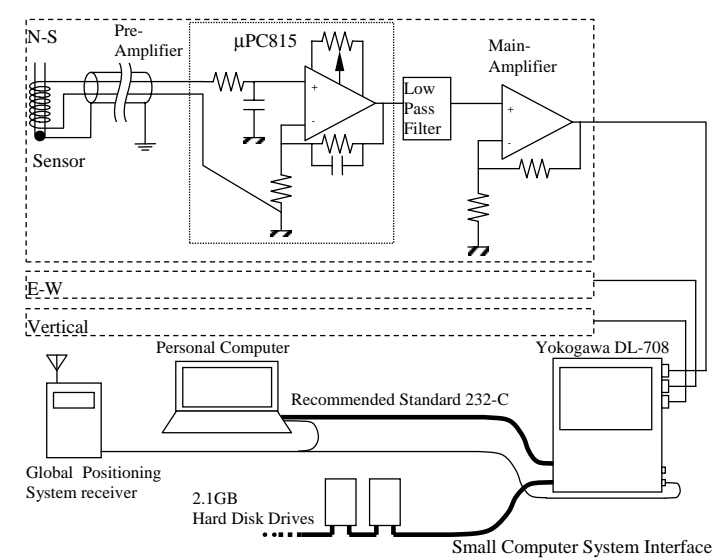

Fig. 2. The observation system of ULF/ELF emissions at Nakatsugawa. The signal oserved by the N-S sensor is fed to a pre-amplifier, then to a low-pass-filter (LPF) and main-amplifier, and stored on the data recorder (DL-708) and saved on a hard disk.

six hours. So there are four files, numbered from file 0 (from $0 \mathrm{~h}$ to $6 \mathrm{~h}$ ) to file 3 ( $18 \mathrm{~h}$ to $24 \mathrm{~h}$ ). The time of the system is controlled by GPS, and a time marker is also recorded. The observation of ULF/ELF emission stops during the time of saving the data on the Hard Disk (i.e. only for five minutes every six hours). These data are regularly collected and we change a Hard Disk to continue the observation.

The data from each channel are analyzed at the university after collection. FFT analysis with the data length of 1024 words gives us the intensity and phase of the magnetic component below $50 \mathrm{~Hz}$.

In addition to this ULF/ELF measurement, three components of magnetic field $\left(B_{X}, B_{Y}, B_{Z}\right)$ in the VLF band below $10 \mathrm{kHz}$ are also observed. These VLF components are digitized by the A/D converter with a sampling frequency of $25 \mathrm{kHz}$ every minute and then analyzed by the FFT method. The amplitude and phase data at $1 \mathrm{kHz}, 3 \mathrm{kHz}, 5 \mathrm{kHz}$ and $9 \mathrm{kHz}$ are saved on a laser disk. These measurements are in-

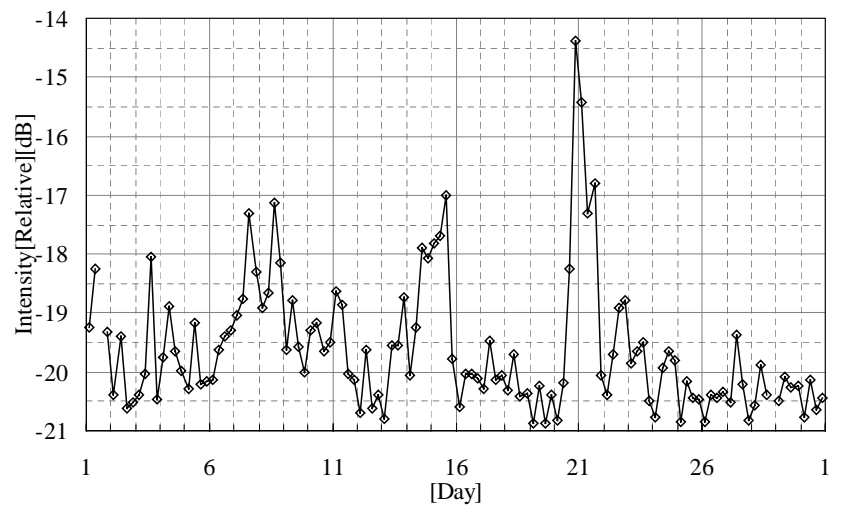

Fig. 3. Temporal evolution of the magnetic field $\left(\sqrt{B_{X}^{2}+B_{Y}^{2}}\right)$ at a frequency of $10 \mathrm{~Hz}$ during 1 to 30 September 1999. Each square indicates the magnetic field intensity averaged over $6 \mathrm{~h}$.

tended to observe seismo-VLF emissions, but these can also be used for this paper to monitor lightning discharges near the observatory. Furthermore, the time calibration of observation is performed with the GPS signal.

\section{Observational results}

Figure 3 illustrates the temporal evolution of the magnetic field intensity (horizontal component, $\sqrt{B_{X}^{2}+B_{Y}^{2}}$ ) at a particular frequency of $10 \mathrm{~Hz}$ (the average over $6 \mathrm{~h}$ ). The electromagnetic radiation of lightning, propagating within the subionospheric waveguide over great distances, is known to be weaker in the ELF band below $50 \mathrm{~Hz}$ (Watt, 1967) because there is little energy in the ELF at the source; only strong lightning discharges, occurring within $100 \mathrm{~km}$ from the receiving station, can be received in the ULF/ELF band by the induction coil. On the other hand, lightning discharge in the VLF, either taking place near the observing station or having propagated within the waveguide over more than several thousand kilometers, is very influential on the receiving level. Figure 3 indicates a higher noise level on 15 September (from 12:00 to 18:00 LT) and on 20 September (from 18:00 to 24:00 LT). Initially we thought that these enhancements were due to the effect of nearby lightning discharges. So, we have investigated the activity of lightning discharges in our VLF record (a frequency of $5 \mathrm{kHz}$ ) at Nakatsugawa. This is shown in Fig. 4a for 15 September and in Fig. 4 b for 20 September. On 15 September we find a enhanced activity of lightning from $30 \mathrm{~min}$ to $4 \mathrm{~h}$ at midnight and from $8 \mathrm{~h}$ to $16 \mathrm{~h}$ during the day. A comparison with lightning data (provided by a weather company) indicates that the former activity is found to occur about $30 \mathrm{~km}$ southeast of the observing station. Also there were many thunderbolts after $8 \mathrm{~h}(60 \mathrm{~km}$ from the station) in different areas including near Shiratori ( $80 \mathrm{~km}$ northwest of the station), Minokamo (50 km west of the station) and Komaki ( $60 \mathrm{~km}$ from the station). There was also heavy rain with many thunderbolts near Gujyo (north- 

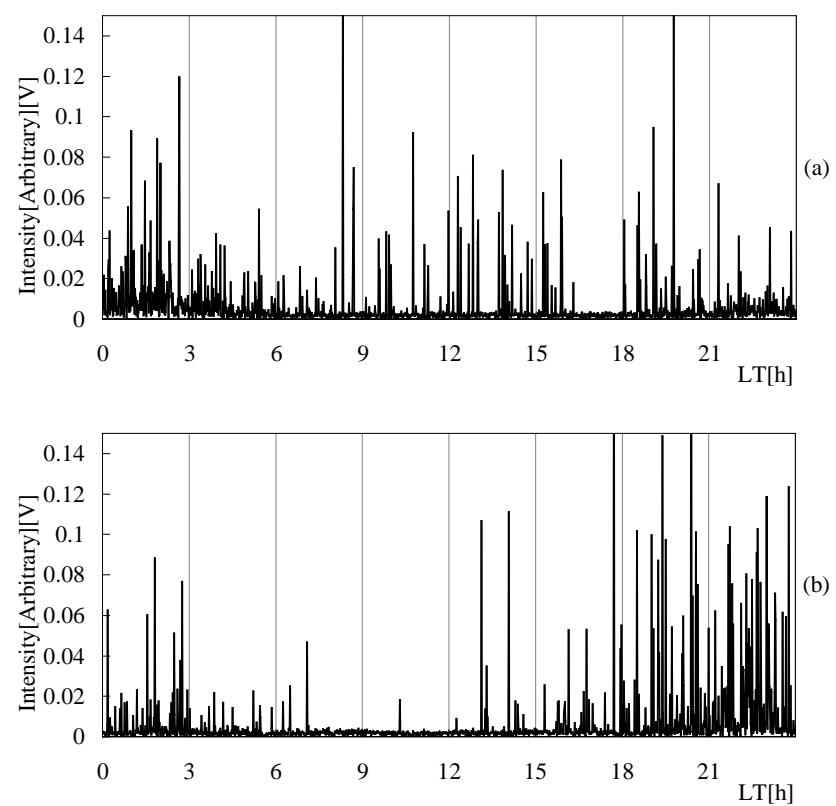

Fig. 4. Temporal evolution of VLF noise level (at $5 \mathrm{kHz}$ ) for 15 September (a) and for 20 September (b).

west direction $65 \mathrm{~km}$ from our observatory) at $14 \mathrm{~h}$; these activities of lightning discharge moved eastward with time. The mountain area from Ontake to Komagatake, $50 \mathrm{~km}$ north of the observatory, became the center of lightning activity at $16 \mathrm{~h}$.

The temporal drift of intensity at $10 \mathrm{~Hz}$ on 15 and 20 September is shown in Figs. 5a and b, respectively. Although the noise level of $10 \mathrm{~Hz}$ is about $-20 \mathrm{~dB}$ at $0 \mathrm{~h}$ in Fig. $5 \mathrm{a}$, a rise in noise level of impulsive noise is found from $0 \mathrm{~h} 30 \mathrm{~min}$ and goes up to $-18 \mathrm{~dB}$ at $4 \mathrm{~h}$. Impulsive noise is also observed from $8 \mathrm{~h}$ to $11 \mathrm{~h}$. Furthermore, fluctuation of noise level appears from $14 \mathrm{~h}$ to $16 \mathrm{~h}$. However, the noise level with some impulsives returns to $-20 \mathrm{~dB}$ (which is the noise level at $0 \mathrm{~h}$ ) roughly after $16 \mathrm{~h}$. This noise level change reflects the atmospherics activity in the VLF shown in Fig. 4a. So we can suggest that the rise in noise level on 15 September, shown in Fig. 3, depends on the activity of lightning discharge occurring within $80 \mathrm{~km}$ of the Nakatsugawa observatory. Also, the enhancements in noise level during a short time in Fig. 3, for example, 3 September, 7 September, 8 September and 11 September are caused by lightning discharge activity within $100 \mathrm{~km}$ from the observatory.

Next, we will examine the noise level change on 20 September. The temporal change at $10 \mathrm{~Hz}$, shown in Fig. $5 b$, indicates that it is at a fixed level of $-20 \mathrm{~dB}$ from $0 \mathrm{~h}$ to $12 \mathrm{~h} 30 \mathrm{~m}$, which means that there is no influence on the noise level of an ELF band like $10 \mathrm{~Hz}$. We can suggest that the atmospheric activity of VLF, detected from $0 \mathrm{~h}$ to $4 \mathrm{~h}$ in Fig. 4b, is due to electromagnetic waves coming from distant places in the subionospheric waveguide. Therefore it is thought that noise level of $10 \mathrm{~Hz}$ is constant. However, in Fig. 5b, an enhancement in noise level is found from $13 \mathrm{~h}$ to
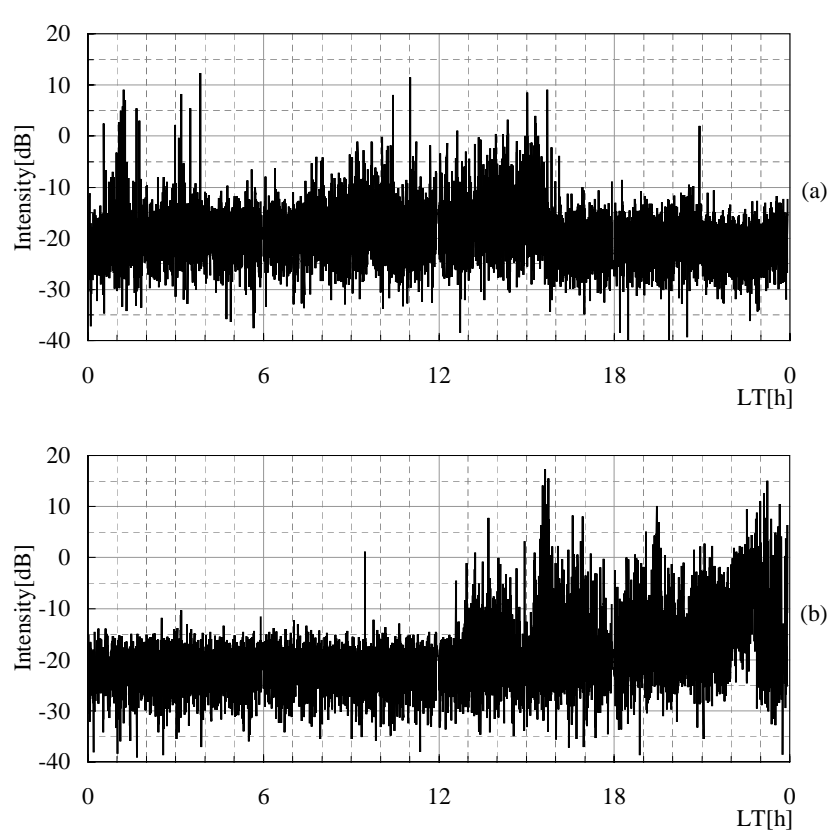

Fig. 5. Temporal evolution of intensity at $10 \mathrm{~Hz}$ on 15 September (a) and on 20 September (b).

$14 \mathrm{~h}$ and from $15 \mathrm{~h}$ to $16 \mathrm{~h}$. The change of atmospheric activity at VLF is also detected in Fig. 4b. The strong lightning discharges occur in the large area from Gujyo to Mt. Ontake, and Ena town, $15 \mathrm{~km}$ west of the observatory. Figure $4 \mathrm{~b}$ shows that this atmospheric activity becomes more intense after $18 \mathrm{~h}$. So the impulsive noise due to lightning discharge is found in Fig. 5b whose atmospheric activity is thought to be within $100 \mathrm{~km}$ from the observatory. Most of the atmospheric activity after $18 \mathrm{~h}$, seen in Fig. $4 \mathrm{~b}$, is due to strong lightning discharges occurring near the observatory, in addition to distant electromagnetic noise. Lightning discharge from $18 \mathrm{~h}$ to $21 \mathrm{~h}$ occurs at Mino district (Inuyama and Hachiman area) and Hida district (west of Mt. Ontake area). Also, lightning discharge at Mino district reoccurs from $21 \mathrm{~h}$ to $22 \mathrm{~h}$ but lightning discharge west of Mt. Ontake moves to the west of Mt. Komagatake. However, lightning discharge at Mt. Komagatake disappears after $22 \mathrm{~h}$ and only lightning discharge in Mino district continues, moves to the east and reaches Mino and Hida district. After that, lightning discharge comes close to $30 \mathrm{~km}$ northwest of the Nakatsugawa observatory at $23 \mathrm{~h}$.

Moreover, the noise level in ELF increases linearly from $21 \mathrm{~h} 30 \mathrm{~min}$ to $23 \mathrm{~h}$, as shown in Fig. 5b. This large enhancement is obviously different from the example of rising noise level caused by lightning discharges from $13 \mathrm{~h}$ to $14 \mathrm{~h}$ or from $15 \mathrm{~h}$ to $16 \mathrm{~h}$ shown in Fig. $5 \mathrm{~b}$. In other words, the noise level of these examples is about $-20 \mathrm{~dB}$ for the background noise and impulsive noise is superposed on this background. It is the superposition of impulsive noise by lightning discharge near the observatory and it generally shows that the noise level of the ELF band without lightning discharge remained at $-20 \mathrm{~dB}$. However, the background noise level from $21 \mathrm{~h}$ 


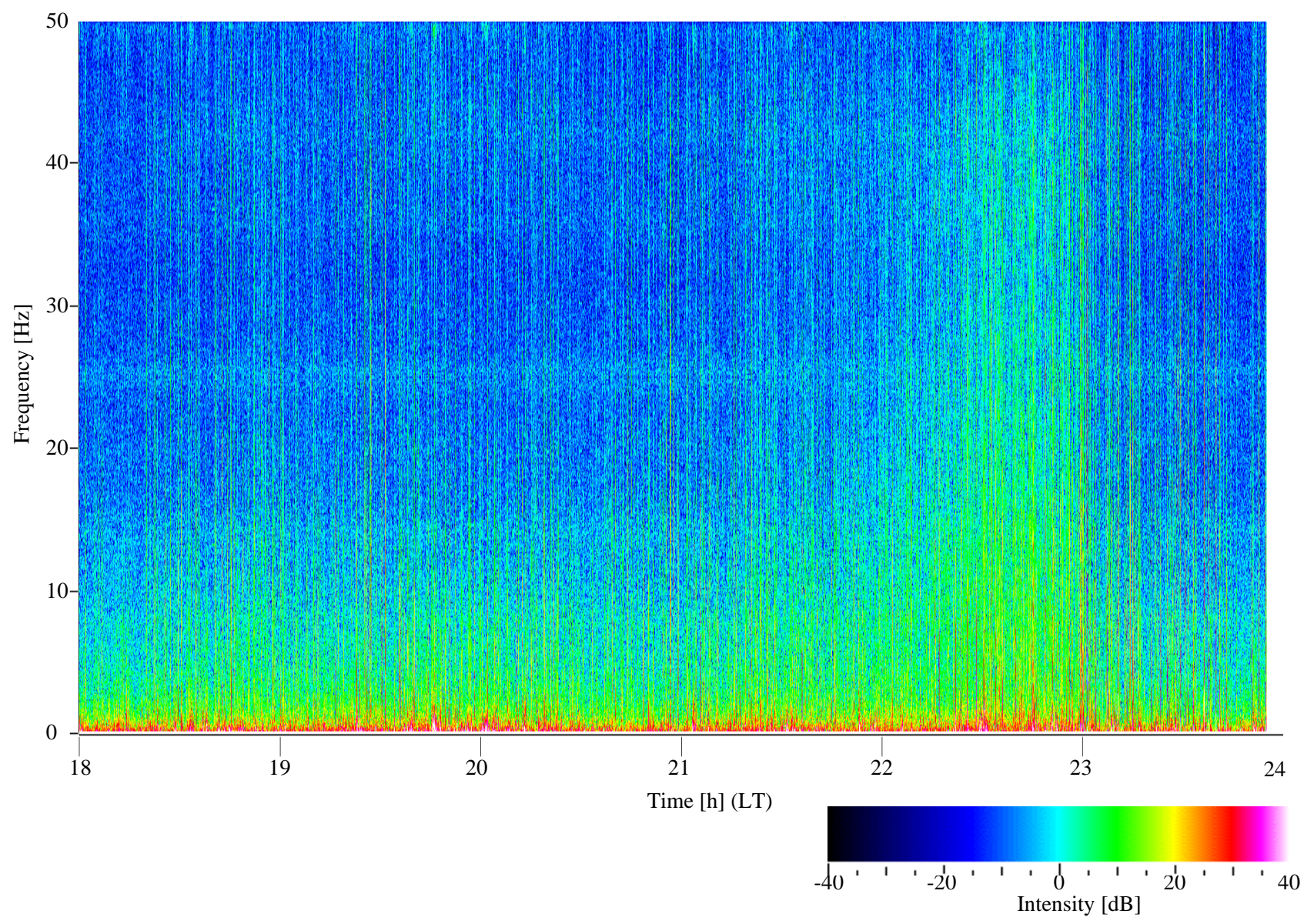

Fig. 6. Dynamic spectrogram during $18 \mathrm{~h}$ to $24 \mathrm{~h}$ on 20 September (in colour format).
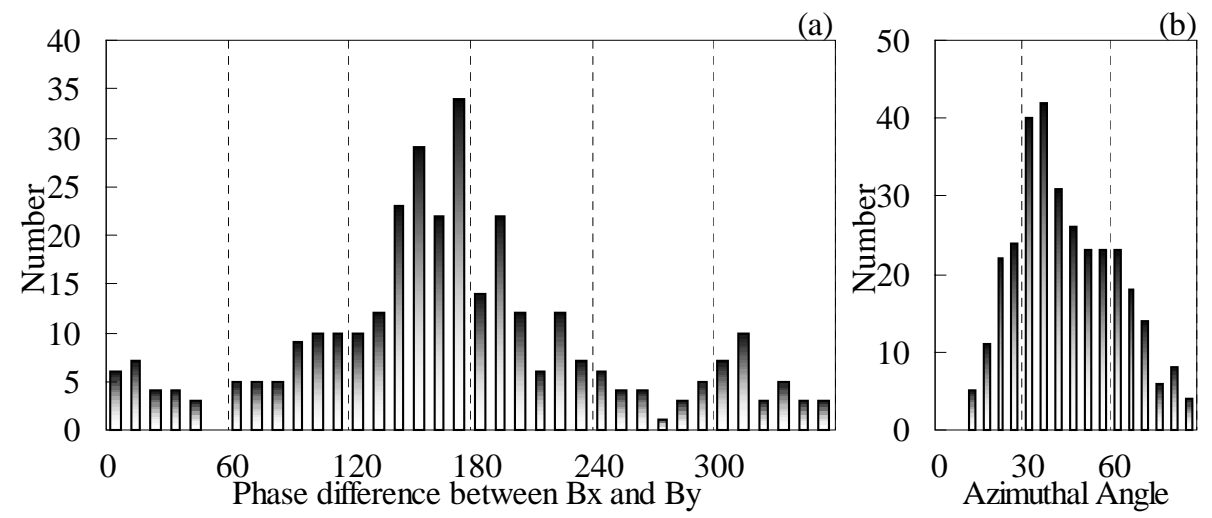

Fig. 7. (a) Phase difference between $B_{X}$ and $B_{Y}$ for the ELF background emission and (b) the corresponding azimuth angle determined by the goniometric method.

$30 \mathrm{~min}$ to $23 \mathrm{~h}$ is found to increase with time by $5 \mathrm{~dB}$ to $10 \mathrm{~dB}$, and impulsive noise is obviously less frequent compared with the example from $13 \mathrm{~h}$ to $14 \mathrm{~h}$ or from $15 \mathrm{~h}$ to $16 \mathrm{~h}$. From these facts, it is clear that the rise in ELF noise level from $21 \mathrm{~h} 30 \mathrm{~min}$ to $23 \mathrm{~h}$ is not dependent on lightning discharges near the observatory.

The dynamic spectrogram from $21 \mathrm{~h} 30 \mathrm{~min}$ to $23 \mathrm{~h}$, for which we have found the rise in ELF noise level, is shown in
Fig. 6. The horizontal axis shows the time from $18 \mathrm{~h}$ to $24 \mathrm{~h}$, and the vertical axis shows the frequency $(0 \mathrm{~Hz}$ to $50 \mathrm{~Hz})$. Impulsive noise from $18 \mathrm{~h}$ to $24 \mathrm{~h}$ is very frequent and this means that strong lightning discharges occur continuously near the observatory. Many impulsive noises are also found from $21 \mathrm{~h} 30 \mathrm{~min}$ to $23 \mathrm{~h}$ in the figure. However, not only impulsive noise but also background noise is found during this time. The evolution of ELF noise on 20 September, shown in 


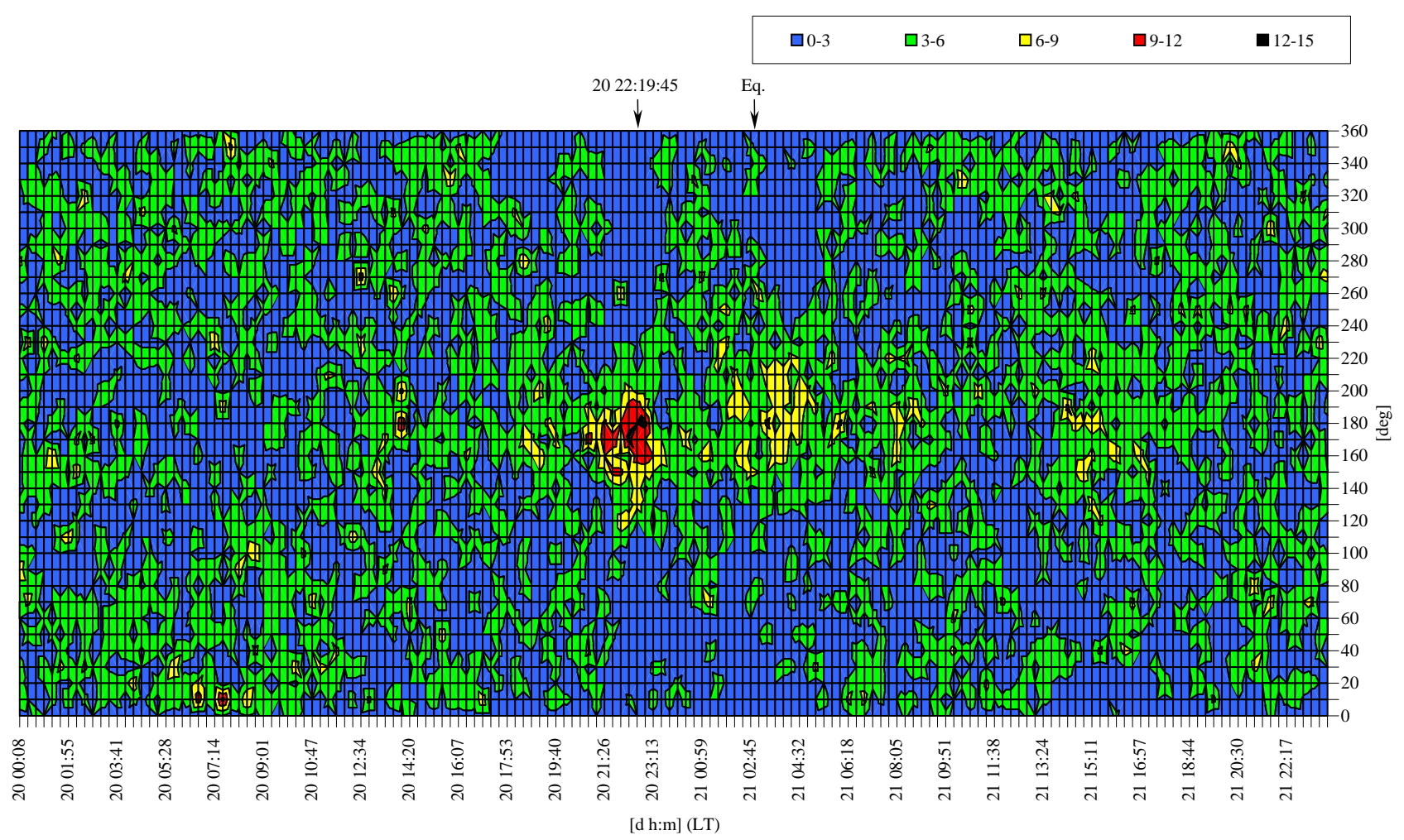

Fig. 8. Temporal evolution of the phase difference $\left(B_{X}\right.$ and $\left.B_{Y}\right)$ at $f=10 \mathrm{~Hz}$. The value on the right-hand side indicates the phase difference between $B_{X}$ and $B_{Y}$ (in degrees) and the occurrence number is given in different colours. Enhanced occurrence of linear polarization is clearly seen during 21:30 to 23:00 JST on 20 September.

Fig. 3, suggests an important finding that the emission band apparently becomes extremely wide-banded up to $50 \mathrm{~Hz}$ and this background noise appears to result in the rise in noise level from $21 \mathrm{~h} 30 \mathrm{~min}$ to $23 \mathrm{~h}$ in Fig. $5 \mathrm{~b}$.

The phase difference (between $B_{X}$ and $B_{Y}$ ) of the background ELF emission during the period (without impulsive noise) from $21 \mathrm{~h} 30 \mathrm{~min}$ to $23 \mathrm{~h}$ on 20 September is shown in Fig. 7a. The median value of the phase difference between $B_{X}$ and $B_{Y}$ is obviously $180^{\circ}$ which means that the observed ELF emission is linearly polarized. This polarization enables us to perform the goniometric direction finding. Figure 7b shows the arrival direction obtained. The peak value of the Gaussian distribution of the arrival direction of background noise is about $35^{\circ}$. The electromagnetic emission at $10 \mathrm{~Hz}$ is found to have propagated to the observatory from some distant place with azimuthal angle from $30^{\circ}$ to $40^{\circ}$, measured from west to south. This azimuthal angle is in good agreement with the direction of Taiwan for which the earthquake of $M=7.6$ occurred at $02: 47$ JST in the early morning on 21 September in 1999.

The importance of the phase difference between $B_{X}$ and $B_{Y}$ of about $180^{\circ}$ is illustrated in Fig. 8, in which the phase difference is plotted in occurrence number as a function of time. Yellow colour in the figure indicates the high occurrence rate at the phase difference just around $180^{\circ}$, and the left-hand group in yellow corresponds to the time interval of the rise in background intensity in Fig. 5b and also to the wideband enhancement in Fig. 6. A similar yellow colour can be seen just around 03:40 JST on 21 September, which is about one hour after the main shock. So, the phase difference between $B_{X}$ and $B_{Y}$ of $\sim 180^{\circ}$ (linear polarization) might be a good indicator that the observed signal originated at a far point, followed by subionospheric propagation.

The increase in background noise at ELF for about $1.5 \mathrm{~h}$ in Fig. $5 \mathrm{~b}$ and Fig. 6, is very likely to be a precursor of the Taiwan earthquake; this enhancement occurred a few hours before the main shock of the earthquake.

\section{Conclusion}

ULF/ELF emission observation at Nakatsugawa has shown that abnormal enhancement in ELF wave activity (up to $50 \mathrm{~Hz}$ ) was observed a few hours (to be more exact, $\sim 5$ to $\sim 4$ hours) before the Taiwan earthquake. A comparison with nearby lightning activity, as measured at VLF $(5 \mathrm{kHz})$, suggests that this ELF noise activity has nothing to do with the lightning activity. The measurement of phase difference between two horizontal magnetic field components shows that the observed ELF emission is linearly polarized, suggesting that it propagates within the subionospheric waveguide over significant distances. Direction finding by the goniometer for these two magnetic components has indicated that the peak 
direction azimuth is around $35^{\circ}$, which is the direction of the epicenter of the Taiwan earthquake (at 01:27 LT of 21 September 1999; magnitude 7.3, depth $11 \mathrm{~km}$ ).

Since the most common source of ULF/ELF emission is related to magnetic storms, we have examined the geomagnetic activity around the period when we observed ULF/ELF emission. The $K p$ index when we observed the ULF/ELF emission (21:30-23:00 JST on 20 September) was 2, which means that the period was geomagnetically extremely quiet. Also, the daily sum of the $K p$ index $(\Sigma K p)$ one day before this time was 15 and one day after this time was 17 . Both indicate that the time period of interest was too quiet to expect a geomagnetic effect from space.

ULF $(f<1 \mathrm{~Hz})$ emission has been found for several large earthquakes as mentioned in the Introduction. However, ULF emission seems to be extended up to the ELF range (up to $50 \mathrm{~Hz}$ ) for this Taiwan earthquake, unlike previous earthquakes. Of course we cannot say anything definite about the mechanism for such ELF waves at the moment but our previous microfracturing mechanism, proposed for the explanation of ULF emission (Molchanov and Hayakawa, 1995), can be applied even for ELF emission in this paper because this earthquake is so shallow $(11 \mathrm{~km})$ that the higher frequency component like ELF can be observed on the ground. Once the ULF/ELF emissions are generated near the Earth's surface, whatever the polarization is, they can propagate in the subionospheric waveguide with small attenuation as $\mathrm{TM}_{0}$ (or TEM) mode (Bliokh et al., 1980); this waveguide acts as a polarization filter so that we could obtain the enhanced linear polarization. We were lucky to observe such ULF/ELF waves.

Acknowledgements. This work was, in part, carried out within the framework of NASDA's (National Space Development Agency of Japan) Earthquake Remote Sensing Frontier Project, which the authors would like to thank for their great support. We also thank the referees for their help in improving the paper.

\section{References}

Bliokh, P. V., Nickolaenko, A. P., and Filippov, Yu. F.: Schumann Resonances in the Earth-ionosphere Cavity, Peter Peregri- nus Ltd., Stevenage, UK, 1980.

Fraser-Smith, A. C., Bernardi, A., McGill, P. R., Ladd, M. E., Helliwell, R. A., and Villard, Jr., O. G.: Low-frequency magnetic field measurements near the epicenter of the Ms7.1 Loma Prieta earthquake, Geophys. Res. Lett., 17, 1465-1468, 1990.

Gokhberg, M. B., Morgunov, V. A., Yoshino, T., and Tomizawa, I.: Experimental measurements of electromagnetic emissions possibly related to earthquakes in Japan, J. Geophys. Res., 87, 78247828, 1982.

Hayakawa, M., (Ed), "Atmospheric and Ionospheric Electromagnetic Phenomena Associated with Earthquakes," Terra Sci. Pub. Co., Tokyo, pp. 996, 1999.

Hayakawa, M. and Fujinawa, Y.: (Eds), "Electromagnetic Phenomena Related to Earthquake Prediction", Terra Sci. Pub. Co., Tokyo, pp. 677, 1994.

Hayakawa, M., Ito, T., and Smirnova, N.: Fractal analysis of geomagnetic ULF data associated with the Guam earthquake on 8 August 1993, Geophys. Res. Lett., 26, 2797-2800, 1999.

Hayakawa, M., Kawate, R., Molchanov, O. A., and Yumoto, K.: Results of ultra-low-frequency magnetic field measurements during the Guam earthquake of 8 August 1993, Geophys. Res. Lett., 23, 241-244, 1996.

Hayakawa, M., Itoh, T., Hattori, K., and Yumoto, K.: ULF electromagnetic precursors for an earthquake at Biak, Indonesia on 17 February 1996, Geophys. Res. Lett., 27, 1531-1534, 2000.

Kawate, R., Molchanov, O. A., and Hayakawa, M.: Ultra-lowfrequency magnetic fields during the Guam earthquake of $8 \mathrm{Au}-$ gust 1993 and their interpretation, Phys. Earth Planet. Inter., 105, 229-238, 1998.

Kopytenko, Yu. A., Matiashvili, T. G., Voronov, P. M., Kopytenko, E. A., and Molchanov, O. A.: Ultra low frequency emission associated with Spitak earthquake and following aftershock activity using geomagnetic pulsation data at observatories Dusheti and Vardziya, Preprint of IZMIRAN, N3(888), Moscow, January, 1990.

Molchanov, O. A. and Hayakawa, M.: Generation of ULF electromagnetic emissions by microfracturing, Geophys. Res. Lett., 22, 3091-3094, 1995.

Molchanov, O. A., Kopytenko, Yu. A., Voronov, P. M., Kopytenko, E. A., Matiashvili, T. G., Fraser-Smith, A. C., and Bernardi, A.: Results of ULF magnetic field measurements near the epicenters of the Spitak $(M s=6.9)$ and Loma Prieta $(M s=7.1)$ earthquakes: Comparative analysis, Geophys. Res. Lett., 19, 14951498, 1992.

Watt, A. D.: VLF Radio Engineering, Pergamon Press, Oxford, 465, 1967. 